OPEN ACCESS

Edited by:

Giuseppe D'Antona,

University of Pavia, Italy

Reviewed by:

Eunjoo An,

Columbia University, United States

Nurel Ertürk,

Hacettepe University, Turkey

*Correspondence:

David Hupin

d.hupin@orange.fr

Specialty section:

This article was submitted to

Exercise Physiology,

a section of the journal

Frontiers in Physiology

Received: 31 December 2021 Accepted: 02 February 2022

Published: 03 March 2022

Citation:

Labeix P, Berger M, Zellag A,

Garcin A, Barthelemy J-C,

Roche F and Hupin D (2022)

Resistance Training of Inspiratory

Muscles After Coronary Artery

Disease May Improve Obstructive

Sleep Apnea in Outpatient Cardiac

Rehabilitation: RICAOS Study.

Front. Physiol. 13:846532.

doi: 10.3389/fphys.2022.846532

\section{Resistance Training of Inspiratory Muscles After Coronary Artery Disease May Improve Obstructive Sleep Apnea in Outpatient Cardiac Rehabilitation: RICAOS Study}

\author{
Pierre Labeix ${ }^{1,2}$, Mathieu Berger ${ }^{1,3}$, Amandine Zellag ${ }^{1,4}$, Arnauld Garcin ${ }^{1,5}$, \\ Jean-Claude Barthelemy ${ }^{1}$, Frederic Roche ${ }^{1,2}$ and David Hupin ${ }^{1,2,6 *}$
}

'SAINBIOSE, U1059 INSERM, University of Lyon, University Jean Monnet, Saint-Etienne, France, ${ }^{2}$ Department of Clinical and Exercise Physiology, University Hospital of Saint-Etienne, Saint-Etienne, France, ${ }^{3}$ Center for Investigation and Research in Sleep, CHUV and UNIL, Lausanne, Switzerland, ${ }^{4}$ Infectious Diseases Department, University Hospital of Saint-Etienne, Saint-Etienne, France, ${ }^{5}$ Innovation and Pharmacology Clinical Research Unit, University Hospital of Saint-Etienne, Saint-Etienne, France, ${ }^{6}$ Department of Medicine, Karolinska Institutet, Solna, Sweden

Background: Obstructive sleep apnea (OSA) affects 5\% of the adult population and its prevalence is up to 13 times higher in coronary artery disease (CAD) patients. However, OSA in this population is less symptomatic, leading to lower adherence to positive airway pressure (CPAP). While oropharyngeal exercise showed a significant decrease in apnea-hypopnea index (AHI) in patients with moderate OSA, there have been no studies testing the impact of specific inspiratory muscle training (IMT) for these patients. The aim of our study was to assess the effectiveness of IMT on AHI reduction in CAD patients with moderate OSA.

Methods: We included patients with CAD involved in a cardiac rehabilitation program and presenting an $\mathrm{AHI}$ between 15 and 30. Patients were randomized in a 1:1 allocation to a control group (CTL - classic training) or an IMT group (classic training + IMT). IMT consisted in 60 deep inspirations a day, 6 days a week, into a resistive load device set at $70 \%$ of the maximum inspiratory pressure (MIP). After 6 weeks, we compared AHI, neck circumference, Epworth Sleepiness Scale, Pittsburgh Sleep Quality index, and quality of life with the 12-item Short Form Survey before and after rehabilitation.

Results: We studied 45 patient $\left(60 \pm 9 \mathrm{y}, \mathrm{BMI}=27 \pm 6 \mathrm{~kg} \cdot \mathrm{m}^{-2}\right)$. The IMT group $(n=22)$ significantly improved MIP $(p<0.05)$ and had a significant decrease in AHI by $25 \%$ $(-6.5 \pm 9.5, p=0.02)$. In the CTL group $(n=23), \mathrm{AHI}$ decreased only by $3.5 \%(-0.7 \pm 13.1$; $p=0.29)$. Between groups, we found a significant improvement in MIP $(p=0.003)$ and neck circumference $(p=0.01)$ in favor of the IMT group. However, we did not find any significant improvement of AHI in the IMT group compared to CTL $(p=0.09)$.

Conclusion: A specific IMT during cardiac rehabilitation contributes to reduce significantly $\mathrm{AHI}$ in CAD patients with moderate OSA. Magnitude of the decrease in OSA severity could be enhanced according to implementation of specific IMT in this population.

Keywords: resistive inspiratory muscle training, obstructive sleep apnea, coronary artery disease, apneahypopnea index, cardiac rehabilitation, oxygen desaturation index 


\section{INTRODUCTION}

Prevalence of moderate to severe obstructive sleep apnea (OSA; apnea plus hypopnea index $>15$ events. $\mathrm{h}^{-1}$ ) is thought to affect up to $23 \%$ of women and $49 \%$ of men (Heinzer et al., 2015). OSA is characterized by recurrent episodes of complete (apneas) or partial (hypopneas) upper airway collapse during sleep. It always stems from obstruction of the pharynx during the inspiratory phase (Fogel et al., 2005).

Several studies have shown that OSA is an independent risk marker and probably risk factor of coronary heart disease (BenAhmed et al., 2014; Tietjens et al., 2019). It is also a major risk factor for cardiovascular morbidity and mortality (Peker et al., 2000; Mooe et al., 2001; Coughlin et al., 2004; Bradley and Floras, 2009). In comparison with other OSA patients, coronary artery disease patients with OSA are characterized by relatively poor diurnal symptoms (Javaheri et al., 1998, 2017; Sin et al., 2002; Arzt et al., 2006). The absence of clinical repercussions may induce a higher withdrawal rate of standard continuous positive airway pressure (CPAP) treatment. Also, for those who have accepted CPAP, long-term adherence remains an important issue (Anandam et al., 2013; McEvoy et al., 2016; Rotenberg et al., 2016; Libman et al., 2017; Askland et al., 2020). Alternative treatments, such as mandibular advancement or surgery, can be proposed for moderate OSA or for patients with limited daytime symptoms but with limited tolerance by some patients over time (Fleury et al., 2010; Giralt-Hernando et al., 2019). Therefore, alternative treatments are needed to reach better acceptance and adherence.

Excessive relaxation of the tongue and soft palate evidenced by a decrease in the EMG pattern of the genioglossus and tensor of the palate muscles (Fogel et al., 2005; Oliven et al., 2019) partly explains the OSA pathogenesis. While physical activity has shown relative effectiveness in improving apneahypopnea index (AHI; Kline et al., 2011; Aiello et al., 2016; Berger et al., 2018, 2021; Hupin et al., 2018), specific exercises of the oropharyngeal area could have a more targeted impact. Thus, Guimarães et al. (2009) have shown that strengthening oropharyngeal muscles by mouth, tongue, and pronunciation exercises reduce AHI in patients with moderate OSA by 8.7 events.h ${ }^{-1}$. An improvement of subjective quality of sleep and a reduction in neck circumference were also found in the "strengthening oropharyngeal muscles" group. In the last decade, several other studies have investigated the effect of respiratory muscle training to decrease the impact of OSA (Vranish and Bailey, 2016; Souza et al., 2018; Ramos-Barrera et al., 2020). Indeed, the resistance strengthening of the inspiratory muscles would have a positive impact on the tone of the oropharyngeal muscles (How et al., 2007). However, these studies proposing inspiratory muscle training were carried out on small sample sizes and none of them were performed with asymptomatic coronary artery disease patients.

The objective of our study was to assess the effects of strengthening inspiratory muscles on AHI in coronary patients with moderate OSA engaged at the same time in a postinfarction cardiac rehabilitation program (CR) using a randomized controlled design. We assessed the benefit of adding an inspiratory resistance muscle training to OSA patients undergoing cardiac rehabilitation (IMT group) compared to a control group undergoing only cardiac rehabilitation (CTL group). We analyzed ventilatory polygraphy data and respiratory muscle strength before and after cardiac rehabilitation.

\section{MATERIALS AND METHODS}

\section{Study Design}

This was a 6 week randomized controlled trial, including on the one hand a control group with cardiac rehabilitation only, and on the other hand an interventional group admitted for $\mathrm{CR}$ and IMT. This study was conducted in the cardiac rehabilitation department at Saint-Etienne university hospital (France). Eligible patients were randomly assigned in a 1:1 allocation.

\section{Patient Characteristics and Eligibility Criteria}

During the initial evaluation, patients had a 24-h Holter ECG monitoring to assess cardiac arrhythmia and to evaluate their very low frequency power spectral density of heart rate increment (VLFI) which is a predictor of sleep disorder (Roche et al., 2002; Sforza et al., 2007). Patients with a high risk of OSA, attested by VLFI $>4 \%$, had a respiratory polygraphy recording to assess OSA severity more accurately. Adult patients initiating a cardiac rehabilitation, under the age of 80 , with an AHI $\geq 15$ and $\leq 30$ events $h^{-1}$ were eligible to participate.

Exclusion criteria were recent thoracic surgery by sternotomy ( $<12$ weeks), obstructive ventilatory disorder with an FEV-1/ FVC ratio $<70 \%$, already treated for OSA.

\section{Ethics Approval and Consent of Participants}

The study was performed from May 2015 to July 2021. Approval and ethical clearance were obtained from an institutional review board (CPP Sud Est I 1408189-2015-A00030-49) which was in accordance with the principles embodied in the Declaration of Helsinki. Prior to study initiation, the objectives of the study were clearly explained to subjects in order to obtain written informed consent. The study was a priori registered at ClinicalTrial.gov (NCT02494648).

\section{Cardiac Rehabilitation CR}

The CR at the Saint-Etienne University Hospital was a 7-week interdisciplinary program that combines interventions performed by cardiologists, nurses, rehabilitation physicians, physiotherapists, dieticians, and psychologists. At the time of enrollment, the patient's functional status was assessed by a cardiopulmonary exercise test (CPET). Exercise training consists of 20 sessions, three times a week (Monday, Wednesday, and Friday) for $1.5 \mathrm{~h}$. Each session starts with a 10 -min warmup period followed by $25 \mathrm{~min}$ of cycling or treadmill (power output at ventilatory threshold defined during the initial CPET) and a 5-min cool down period. Resistance 
muscle training of upper and lower limbs is also offered. The workout was divided into $80 \%$ aerobic and $20 \%$ resistance exercises. The first week of CR, continuous endurance exercises were preferred, and from the second week, interval exercises were added. An expert physiotherapist and an adapted physical activity monitor supervised sessions with continuous heart rate and pulse oximetry monitoring. The workload progression was adjusted weekly according to the patient's tolerance (Borg Perceived Effort Scale). Patients attended weekly hour-long group sessions with healthcare professionals aimed at reinforcing their health education. Particular emphasis is provided on understanding the pathophysiology of coronary artery disease, the role of cardiovascular risk factors, and its management, mainly through physical activity, anxiety control, smoking cessation, nutritional balance, and adherence to guidelines for recommended drugs.

\section{Interventional Group (IMT)}

The interventional group followed the $\mathrm{CR}$ program described above, as well as a 6-week IMT. To strengthen the inspiratory muscles, we used a resistive loading device (POWERbreathe ${ }^{\circledR}$ Plus medium resistance, Southam, United Kingdom) with a flowindependent one-way valve to ensure consistent resistance and an adjustable specific pressure setting (from -23 to $-186 \mathrm{cmH}_{2} 0$ ). IMT consisted of performing 6 days a week, two sessions of 30 inspirations against a load of 70\% MIP, during the entire duration of the CR period, i.e., nearly 40 sessions in 6 weeks. On days when the patient was present at the CR center, the IMT sessions were carried out under the supervision of the physiotherapist (PL). The third week, the MIP was reevaluated in the same conditions as during inclusion in order to adjust the training load. Patients were asked to keep a training notebook with indication of the difficulty in performing the session on a $0-5$ scale.

\section{Control Group}

Patients randomized in the control group participated only in the CR and performed the same evaluations as the IMT group at baseline and at follow-up.

\section{Outcome Measures}

All outcome measures described were performed at baseline and at 6-week follow-up.

Respiratory polygraphic data. AHI was the main outcome measured from respiratory polygraphy. Ambulatory polygraphy was performed at home using either a Nox-T3 (Nox Medical, Reykjavik, Iceland) or a VistaO ${ }_{2}$ flux (Novacor, Rueil Malmaison, France). For both devices, the signals acquired were the following: nasal flow with pressure transducer and oxygen saturation with a digital pulse oximeter (Nonin, United States). For Nox-T3, respiratory signals were recorded with chest and abdominal respiratory inductance plethysmography belts. For $\mathrm{VistaO}_{2}$ flux, respiratory signals were evaluated by thoracic impedance sensors embedded in a multimodal ECG Holter recorder (Roche et al., 1999; Poupard et al., 2008; Chouchou et al., 2013). For each patient, the second polygraphy at the end of the study was carried out with the same device as baseline in order to be more consistent. In accordance with the 2012 American Academy of Sleep Medicine guidelines (Berry et al., 2012), an apnea was defined as a cessation in airflow ( $\geq 90 \%$ baseline) for $\geq 10$ s, and a hypopnea was defined as a reduction in airflow ( $\geq 30 \%$ baseline) for $\geq 10$ s which resulted in $a \geq 4 \%$ oxygen desaturation. Sleep apnea severity was rated in accordance with the individual's AHI, defined as the total number of apneas and hypopneas per hour of sleep and oxygen desaturation per hour of sleep; where an AHI of 5-15 events. $\mathrm{h}^{-1}$ was defined as mild, 16-30 moderate, and $>30$ designated as severe OSA. Secondary polygraphic outcomes included oxygen desaturation index (ODI), central apnea index, the mean and the lowest oxyhemoglobin saturation $\left(\mathrm{SpO}_{2}\right)$, and the percentage of time with a $\mathrm{SpO}_{2}$ under $90 \%$ $(\mathrm{SpO} 2<90 \%)$.

Respiratory function assessment. Lung function was assessed by standard spirometry and included forced expiratory volume in $1 \mathrm{~s}$ (FEV-1), forced vital capacity (FVC), and peak expiratory flow in accordance with the guidelines of the European Respiratory Society (Laveneziana et al., 2019). Maximal inspiratory pressure (MIP) was obtained with a specific device (POWERbreathe $\mathrm{KH} 2$, POWERbreathe International Ltd., Southam, United Kingdom). The maneuvers were carried out with the patient seated and knees flexed to $90^{\circ}$ and were performed using the residual volume to realize a forced inspiration. Maximal inspiratory pressure was determined as the highest average pressure over $1 \mathrm{~s}$ reached during exercise. We considered three valid maneuvers (coefficient of variation below 10\%) and the highest value was used for IMT.

Surveys. We analyzed questionnaires evaluating subjective sleep quality and quality of life. Subjective daytime sleepiness was measured by the Epworth Sleepiness Scale (ESS) which evaluates the propensity to sleep from "no" (scored 0) to "intense" (scored 3) in eight different situations. A total score $>10$ indicates excessive daytime sleepiness (Johns, 1991). Quality of sleep was evaluated with the Pittsburgh Sleep Quality Index (PSQI), which is a questionnaire that evaluates seven sleep components on a scale from 0 (no difficulty) to 3 (severe difficulty). The results are expressed as a global score (ranging from 0 to 21). A total score $>5$ indicates poor sleep quality (Buysse et al., 1989). The 12-item Short Form Survey (SF-12) was used to assess self-reported health-related quality of life, which evaluates physical health with a range of 23.99 (poor) to 56.58 (good) and mental health with a range of 19.06 (poor) to 60.76 (good; Ware et al., 1996).

\section{Statistical Data Analysis}

Descriptive and inferential analyses were performed using GraphPad Prism 6 (GraphPad, San Diego, United States). Characteristics of the sample and treatment effect between groups were assessed using Student's $t$-test for independent samples. Pre-versus post-CR differences were examined using paired $t$-tests, and chi-square test corrected by Fisher's exact test was used for the categorical variables. The results are shown as mean \pm standard deviation, number and percentage, and as differences of means and confidence interval (95\%). Statistical significance was set at a two-tailed $p<0.05$. 
The sample size calculation was based on the Puhan et al. (2006) study results. For an expected difference of 7 points of AHI between the two groups, with a statistical power of $90 \%$, we calculated a sample size of 44 patients. To consider dropouts before the end of the rehabilitation program, we decided to include 48 patients.

\section{RESULTS}

\section{Demographics and Baseline Characteristics}

During the inclusion period, 636 patients were admitted to our cardiac rehabilitation center and 191 patients (40\%) were assessed for suspected OSA. After respiratory polygraphy, $44.5 \%$ $(n=85)$ had $\mathrm{AHI}>30$ events. $\mathrm{h}^{-1}$ and $29.8 \% \quad(n=57)$ had AHI $<15$ events. $h^{-1}$, and 48 patients with an AHI between 15 and 30 events. $\mathrm{h}^{-1}$ were included in our study. The flowchart of the study is depicted in Figure 1. Baseline clinical characteristics of the study population are summarized in Table 1. Analyses of characteristics showed no significant differences at baseline.

\section{Change in Characteristics}

The post-intervention change in BMI was not significantly different between groups (Table 2). In the IMT group, neck circumference decreased by $0.5 \pm 0.9 \mathrm{~cm}(p=0.02)$, and the

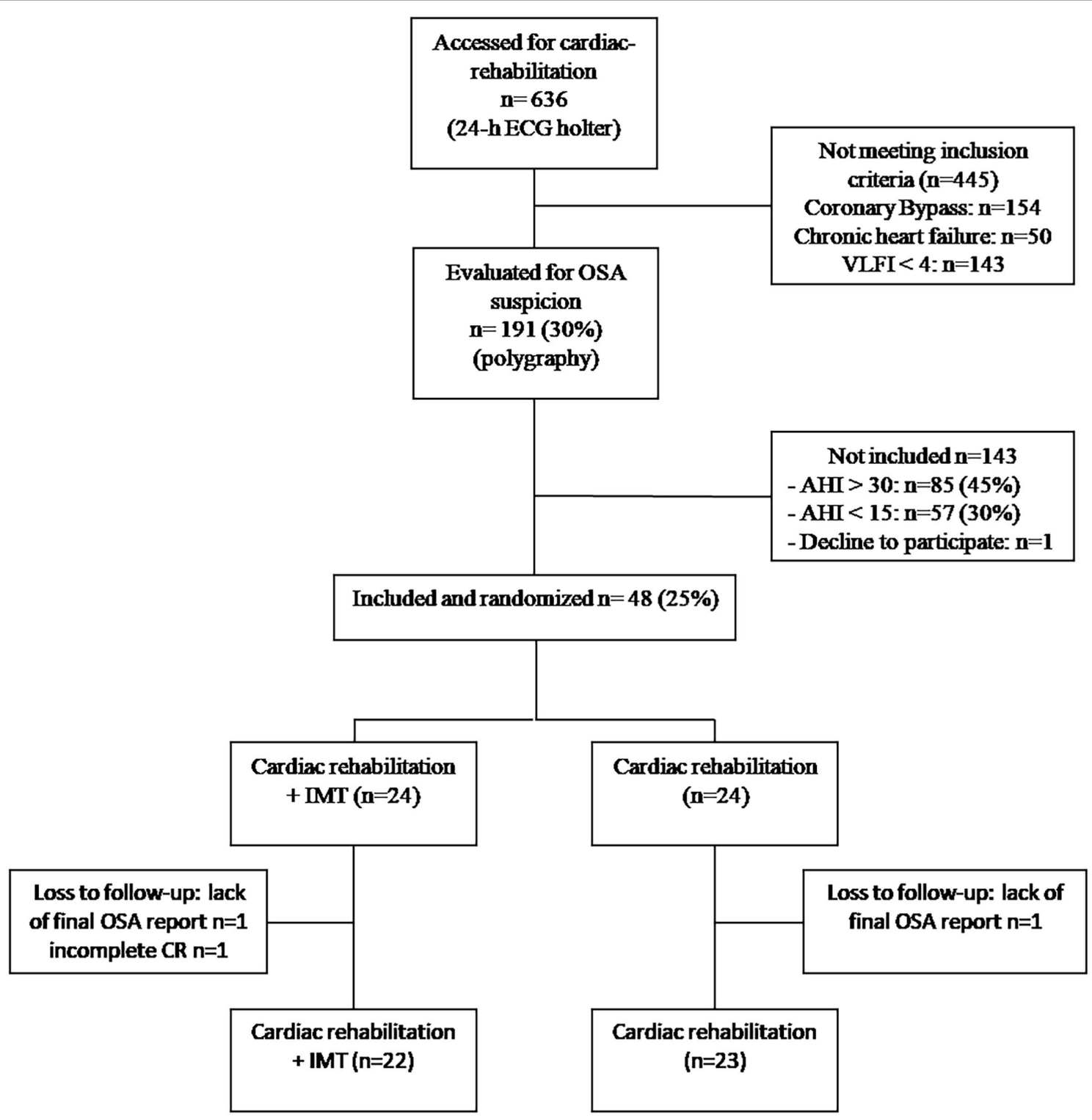

FIGURE 1 | Flowchartof the study. OSA, obstructive sleep apnea; AHI, apnea-hypopnea index; IMT, inspiratory muscle training; CR, cardiac rehabilitation; and $\mathrm{VLFI}$, very low frequency power spectral density of heart rate increment. 
difference between groups was also significant after intervention $(p=0.01)$. MIP significantly increased with the IMT intervention compared to the control ( $p=0.003$; Table 2).

\section{Cardiopulmonary Exercise Test}

At the end of the cardiac rehabilitation, both groups showed a significant improvement in maximal oxygen uptake from $20.7 \pm 4.9$ before CR to $24.7 \pm 5.6\left(\mathrm{ml}^{-1} \mathrm{~min}^{-1} \mathrm{~kg}^{-1} ; p<0.0001\right)$ after CR for the IMT group and from 20.6 \pm 4.9 before CR

TABLE 1 | Baseline characteristics.

\begin{tabular}{|c|c|c|c|}
\hline & $\begin{array}{c}\text { CTL Group } \\
n=23\end{array}$ & $\begin{array}{c}\text { IMT Group } \\
\quad n=22\end{array}$ & Value of $p$ \\
\hline Age (y) & $59.3 \pm 10.3$ & $61.0 \pm 8.4$ & 0.55 \\
\hline Females & $4(18)$ & $1(4)$ & \\
\hline Height (cm) & $173.0 \pm 8.4$ & $169.5 \pm$ & 0.21 \\
\hline Weight (kg) & $83.9 \pm 18.9$ & $81.0 \pm 14.1$ & 0.58 \\
\hline $\mathrm{BMl}$ & $28.1 \pm 5.8$ & $27.9 \pm 4.1$ & 0.91 \\
\hline Neck size $(\mathrm{cm})$ & $40.1 \pm 2.6$ & $38.8 \pm 2.8$ & 0.15 \\
\hline High blood pressure & $8(35)$ & $10(42)$ & 0.64 \\
\hline Dyslipedemia & $9(39)$ & $7(29)$ & 0.55 \\
\hline Smokers & $13(57)$ & $14(58)$ & 0.65 \\
\hline Diabetes & $6(26)$ & 7 (29) & 0.82 \\
\hline Obesity & $6(26)$ & $9(38)$ & 0.41 \\
\hline LVEF (\%) & $53.9 \pm 9.6$ & $57 \pm 9.4$ & 0.28 \\
\hline \multicolumn{4}{|l|}{ Coronary intervention } \\
\hline Thrombolysis & $3(13)$ & $6(25)$ & 0.31 \\
\hline Angioplasty without stent & $3(13)$ & $3(13)$ & 0.96 \\
\hline Single-stem stent & $13(57)$ & $10(42)$ & 0.25 \\
\hline Multi-stem stents & $8(34)$ & $10(42)$ & 0.53 \\
\hline \multicolumn{4}{|l|}{ Treatment } \\
\hline Beta blocker & $20(87)$ & $18(75)$ & 0.31 \\
\hline Aspirin & $21(91)$ & $21(88)$ & 0.68 \\
\hline Double APT & $23(100)$ & $23(96)$ & 0.33 \\
\hline Statin & $21(91)$ & $17(71)$ & 0.08 \\
\hline ACEI/ARB & $19(83)$ & $18(75)$ & 0.53 \\
\hline FEV-1\% & $99.0 \pm 13.7$ & $97.2 \pm 19.1$ & 0.78 \\
\hline
\end{tabular}

Values are mean \pm standard deviation or $n(\%)$. BMI, body mass index; LVEF, left ventricular ejection fraction; APT, anti-platelet; ACEI/ARB, angiotensin-converting enzyme inhibitor/angiotensin receptor blocker; and FEV-1, Forced expiratory volume in $1 \mathrm{~s}$. to $23.7 \pm 5.3\left(\mathrm{ml}^{-1} \mathrm{~min}^{-1} \mathrm{~kg}^{-1} ; p=0.0003\right)$ after CR for the control group. Maximum power output during CPET after CR increased by $23.6 \pm 23.7 \mathrm{~W}(p<0.0001)$ for the IMT group and by $27.5 \pm 22.9 \mathrm{~W}(p<0.0001)$ for the control group Table 2 .

\section{Polygraphic Data}

At baseline, polygraphy data between groups were similar (Table 3). Post-intervention, the mean reduction in AHI score was only significant for the IMT group, which showed a decrease of $6.5 \pm 9.5$ events. $^{-1}$ (95\% CI: 2.015 to $\left.10.08, p=0.005\right)$. By contrast, the control group which only carried out the CR showed a nonsignificant decrease of $0.7 \pm 13.4$ events. $^{-1}$ (Table 3; Figure 2). The difference in AHI of $5.8 \pm 3.2$ points between the two groups was close to significance $(p=0.09)$. ODI was significantly decreased in the IMT group by $6.4 \pm 8.02$ events. $\mathrm{h}^{-1}$ (95\% CI: -9.910 to $\left.-2.977, p=0.0009\right)$; for the CTL group, no significant change in ODI was observed $(p=0.14)$. If we only consider the obstructive part of sleep apnea (AHI minus central apnea index), we observed a significant decrease of $6.7 \pm 8.5$ events.h ${ }^{-1}(p=0.004)$.

\section{Questionnaires}

ESS only decreased significantly for the IMT group $(-2.2 \pm 3.2$ points, $p=0.0176)$, and PSQI was close to significant with a mean score below $5(3.9 \pm 1.6, p=0.053)$. For the mental health score of SF-12, the IMT group showed a significant increase of $5.58 \pm 7.4$ points $(p=0.008)$, while it did not change in the CTL group $(p=0.7)$. As a result, we found for this mental health score a significant difference between groups of $6.5 \pm 2.6$ points $(p=0.01)$. We found no other significant difference in the questionnaires, either intragroup or intergroup (Table 3).

\section{DISCUSSION}

Our study showed that 6 weeks of resistance IMT in patients with moderate OSA admitted in cardiac rehabilitation for

TABLE 2 | Average values of characteristics and cardiopulmonary exercise test obtained before and after cardiac rehabilitation in the control (CTL) and inspiratory muscle training (IMT) groups.

\begin{tabular}{|c|c|c|c|c|c|c|c|}
\hline & \multicolumn{3}{|c|}{ CTL group } & \multicolumn{3}{|c|}{ IMT group } & \multirow{2}{*}{$\begin{array}{l}\text { Value of } p \\
\text { intergroup }\end{array}$} \\
\hline & Before & After & Value of $p$ & Before & After & Value of $p$ & \\
\hline \multicolumn{8}{|l|}{ Characteristics } \\
\hline Weight (kg) & $81.0 \pm 14.1$ & $83.9 \pm 18.9$ & 0.92 & $83.9 \pm 18.9$ & $80.2 \pm 14.3$ & 0.09 & 0.16 \\
\hline $\mathrm{BMI}$ & $27.9 \pm 4.1$ & $28.1 \pm 5.9$ & 0.83 & $28.1 \pm 5.8$ & $27.4 \pm 3.8$ & 0.07 & 0.11 \\
\hline Neck circumference (cm) & $40.1 \pm 2.6$ & $40.5 \pm 2.2$ & 0.18 & $38.8 \pm 2.8$ & $38.3 \pm 3.1$ & 0.02 & 0.01 \\
\hline $\mathrm{MIP}\left(\mathrm{cmH}_{2} \mathrm{O}\right)$ & $89.6 \pm 17.7$ & $92.4 \pm 22.3$ & 0.65 & $97.6 \pm 29.7$ & $115.4 \pm 30.2$ & 0.0004 & 0.003 \\
\hline \multicolumn{8}{|l|}{ Cardiopulmonaryexercise test } \\
\hline $\mathrm{VO}_{2}$ peak $\left(\mathrm{ml}^{-1}\right.$. $\left.\mathrm{min}^{-1} . \mathrm{kg}^{-1}\right)$ & $20.6 \pm 4.9$ & $23.7 \pm 5.3$ & 0.0003 & $20.7 \pm 4.9$ & $24.7 \pm 5.6$ & $<0.0001$ & 0.19 \\
\hline $\operatorname{Pmax}(\mathrm{W})$ & $133.6 \pm 39.3$ & $164.4 \pm 39.2$ & $<0.0001$ & $136.9 \pm 32.3$ & $159.4 \pm 48.9$ & $<0.0001$ & 0.59 \\
\hline Heart rate at peak (\% predicted) & $75.3 \pm 11.9$ & $81.9 \pm 13.5$ & 0.02 & $79.8 \pm 15.9$ & $80.7 \pm 14.1$ & 0.57 & 0.15 \\
\hline
\end{tabular}

Values are mean \pm standard deviation. Significant values $(p<0.05)$ are indicated in bold.

BMI: body mass index; MIP: maximum inspiratory pressure; VO2peak: maximal oxygen uptake; Pmax: maximal power output. . 
TABLE 3 | Average values of polygraphy and questionnaires before and after cardiac rehabilitation in the control (CTL) and inspiratory muscle training (IMT) groups.

\begin{tabular}{|c|c|c|c|c|c|c|c|}
\hline & \multicolumn{3}{|c|}{ CTL group } & \multicolumn{3}{|c|}{ IMT group } & \multirow[b]{2}{*}{$\begin{array}{l}\text { Value of } p \\
\text { intergroup }\end{array}$} \\
\hline & Before & After & Value of $p$ & Before & After & Value of $p$ & \\
\hline \multicolumn{8}{|l|}{ Polygraphic recording } \\
\hline $\mathrm{AHI}\left(\right.$ events. $\left.\mathrm{h}^{-1}\right)$ & $22.0 \pm 7.1$ & $21.4 \pm 13.9$ & 0.29 & $24.9 \pm 7.8$ & $18.8 \pm 10.1$ & 0.003 & 0.09 \\
\hline ODI (events.h-1) & $22.5 \pm 5.2$ & $21.4 \pm 14.1$ & 0.14 & $23.1 \pm 8.0$ & $16.6 \pm 9.6$ & 0.0004 & 0.12 \\
\hline Hypopnea Index (events.h-1) & $14.1 \pm 5.1$ & $14.8 \pm 13.1$ & 0.45 & $15.4 \pm 4.9$ & $11.8 \pm 6.1$ & 0.03 & 0.15 \\
\hline Obstructive apnea Index (events.h-1) & $6.9 \pm 3.5$ & $6.4 \pm 4.6$ & 0.33 & $6.3 \pm 5.6$ & $4.0 \pm 3.2$ & 0.02 & 0.29 \\
\hline Obstructive part of OSA (events.h-1) & $21.2 \pm 4.9$ & $21.8 \pm 16.0$ & 0.29 & $21.8 \pm 7.1$ & $15.8 \pm 7.7$ & 0.004 & 0.09 \\
\hline Central apnea Index (events. $h^{-1}$ ) & $1.7 \pm 2.3$ & $1.1 \pm 1.1$ & 0.37 & $2.4 \pm 2.9$ & $1.4 \pm 1.8$ & 0.32 & 0.78 \\
\hline Lowest $\mathrm{SpO}_{2}(\%)$ & $83.8 \pm 2.7$ & $82.9 \pm 5.2$ & 0.57 & $83.3 \pm 4.1$ & $85.7 \pm 2.2$ & 0.08 & 0.12 \\
\hline Mean $\mathrm{SpO}_{2}(\%)$ & $92.5 \pm 1.6$ & $92.1 \pm 1.7$ & 0.52 & $93.0 \pm 1.4$ & $93.4 \pm 1.4$ & 0.30 & 0.14 \\
\hline $\mathrm{SpO} 2<90 \%(\min )$ & $13.7 \pm 17.5$ & $24.8 \pm 57.5$ & 0.33 & $12.3 \pm 26.6$ & $4.6 \pm 6.3$ & 0.25 & 0.13 \\
\hline \multicolumn{8}{|l|}{ Questionnaires } \\
\hline ESS & $7.4 \pm 3.6$ & $6.2 \pm 4.0$ & 0.24 & $7.3 \pm 5.2$ & $4.3 \pm 2.9$ & 0.02 & 0.26 \\
\hline PSQI & $6.0 \pm 3.7$ & $5.4 \pm 3.2$ & 0.28 & $6.1 \pm 3.7$ & $3.9 \pm 1.6$ & 0.053 & 0.38 \\
\hline SF-12 mental score & $46.4 \pm 9.6$ & $48.8 \pm 8.8$ & 0.68 & $44.6 \pm 11.2$ & $52.3 \pm 9.6$ & 0.008 & 0.013 \\
\hline SF-12 physical score & $44.4 \pm 9.6$ & $44.9 \pm 10.5$ & 0.80 & $41.2 \pm 10.0$ & $42.6 \pm 12.5$ & 0.30 & 0.70 \\
\hline
\end{tabular}

Values are mean \pm standard deviation. AHI, apnea-hypopnea index; ODI, oxygen desaturation index, OSA, obstructive sleep apnea; SpO ${ }_{2}$, oxygen saturation value; ESS, Epworth Sleepness Scale; PSQI, Pittsburgh Sleep Quality Index; and SF-12, 12-itemShort Form Survey. Significant values $(p<0.05)$ have been indicated in bold.

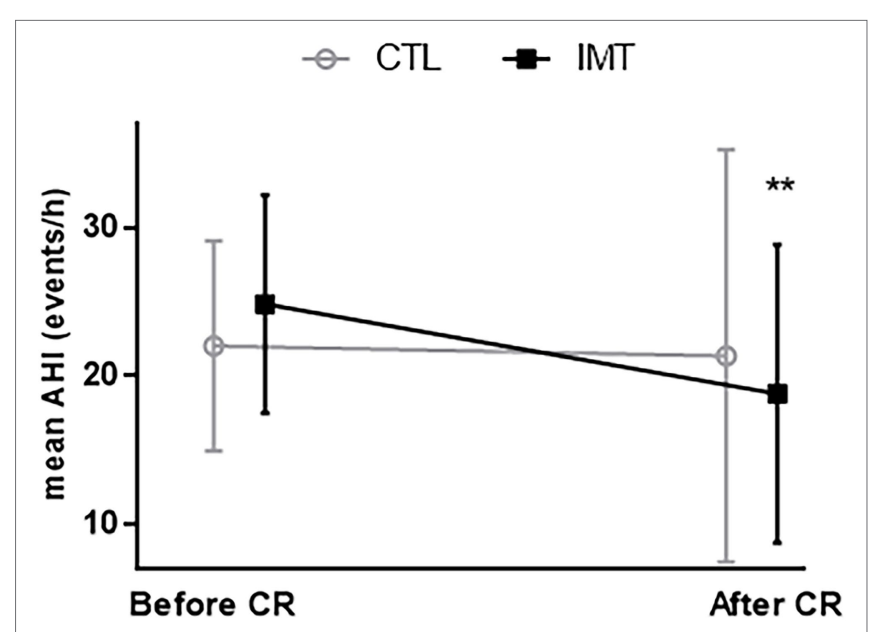

FIGURE 2 | Evolution of apnea-hypopnea index (AHI) before and after cardiac rehabilitation (CR). ${ }^{* *} p=0.003$; significant decrease of $\mathrm{AHI}$ after cardiac rehabilitation only for IMT group (black square).

coronary artery disease allowed a decrease in AHI and ODI. This is in line with the effect of IMT on pharyngeal tone. In this sense, How et al. (2007) showed in awake subjects with calm breathing that an acute bout of inspiratory muscle exercise allowed to increase the activation of specific upper airway dilator muscles and that an IMT could, by increasing the passive tone of the upper airway dilatators, be more favorable in OSA patients with greater compliance of their pharyngeal wall (Isono et al., 1997).

In our study, patients undergoing IMT showed an improvement of their MIP (+ 18\%). Although not measured, we hypothesize that IMT, initially focused on improving diaphragmatic strength and probably endurance, also allowed an improvement of the upper airway dilatator muscle tone during sleep. The decrease in the obstructive part of the sleep disorders recorded (AHI minus central apnea index) suggests that IMT could reduce collapsibility of the upper airway during sleep, even in the absence of neural drive. According to a study by Guimarães et al. (2009), in patients who performed oropharyngeal exercises for 12 weeks, the authors suggested an upper airway remodeling linked to a significant decrease in neck circumference. They also showed that these changes in neck circumference were negatively correlated with improvement in AHI. Finally, in our study, the significant decrease in neck circumference might be related to the improvement in the tone of the upper airway, which would require further investigational studies.

Noteworthy, IMT allowed a significant reduction in hypoxemic load in the present study. In fact, in the IMT group, the patients presented a significantly lower ODI and a decrease in the time spent below $90 \%$ of $\mathrm{SpO} 2$ after intervention. The improvement of these factors is of strong interest in the management of coronary patients with OSA considering the major role of intermittent hypoxemia in terms of morbidity and mortality as well as in the development of cardiovascular risk factors (Garvey et al., 2009; Dewan et al., 2015).

Our results suggest that, at baseline, coronary patients with moderate OSA present few OSA-related symptoms. Indeed, the subjective daytime sleepiness scores assessed by the Epworth questionnaire before $\mathrm{CR}$ were $<10$ (which would indicate excessive daytime sleepiness) in the whole population, while the patients reported poor sleep quality. Of note, cardiac rehabilitation had no significant effect on these two scores in the control group. On the other hand, in the IMT group, the significant improvement in AHI is in line with a significant improvement in daytime sleepiness as well as an improvement of sleep quality. Due to the high prevalence of OSA in the population with coronary artery disease $(69 \%$ of our patients 
were assessed for suspicion of OSA; Hupin et al., 2018), it seems important to systematically look for sleep disorders in patients who have had a heart attack.

\section{STRENGTHS AND LIMITATIONS}

The strength of our study was its randomized controlled design with an easy access IMT device, an IMT simple to perform and requiring little daily training time (60 repetitions per day, i.e.,20 min). Patient feedbacks were very positive, whereby most found a benefit and continued IMT after the end of their cardiac rehabilitation. Another strength of our study is the centralized blind reading of the polygraphic signals avoiding any analysis bias.

Our study also had limitations. First, we did not find any significant difference between the group performing IMT in addition to $\mathrm{CR}$ compared to the group performing $\mathrm{CR}$ alone. This lack of difference could be explained by the fact that physical training per se, as provided during $\mathrm{CR}$, could improve the $\mathrm{AHI}$ in some patients included in the control group (Berger et al., 2018). Indeed, physical exercise could decrease fat mass (Kline et al., 2011; Desplan et al., 2014), greater overall muscle tone, and improved respiratory function (Sengul et al., 2009). This set of elements may have reduced the impact of IMT in our study. Indeed, physical training induces an increase in voluntary ventilation which, in the long term, allows better ventilatory control, an increased sensitivity to respiratory drive, and an increase in the strength of the inspiratory muscles (a median increase of +7 $\mathrm{cmH}_{2} \mathrm{O}$ was observed for the control group and a maximum gain of $22 \mathrm{cmH}_{2} \mathrm{O}$ for a patient). This slight increase in MIP may have resulted in a lower rate of complete obstructive apnea in favor of a higher rate of hypopnea in the control group.

Another limitation to note is the lack of objective evaluation of adherence to IMT training since the device used is mechanical and does not have a repetition counter. For the sake of more precise evaluation, the use of an electronic device would have allowed rigorous monitoring of the training. Finally, our study did not allow to establish a causality link between improved MIP and increased resistance to upper airway collapse during sleep. Future physiological studies evaluating the effect of IMT on upper airway closure pressures during sleep are needed to confirm our data.

\section{CLINICAL IMPLICATION AND CONCLUSION}

In case of CPAP treatment failure, it appears necessary to offer various alternatives to OSA patients to reduce the severity of sleep disorders. In that view, our study brings

\section{REFERENCES}

Aiello, K. D., Caughey, W. G., Nelluri, B., Sharma, A., Mookadam, F., and Mookadam, M. (2016). Effect of exercise training on sleep apnea: a systematic review and meta-analysis. Respir. Med. 116, 85-92. doi: 10.1016/J.RMED. 2016.05.015 a new piece to the puzzle by showing that a simple IMT exercise, performed daily, could reduce OSA severity in nontreated patients. In the most severe patients, this treatment could also be offered in addition to CPAP to reduce the pressures insufflated into the airways and thus improve patient comfort. Further investigational studies are needed to determine the best IMT modality (strength training or endurance training) and the potential combined effect with expiratory muscle training, as previously shown by Puhan et al. (2006) and Ward et al. (2012).

In conclusion, IMT for 6 week decreases AHI in coronary patients with moderate asymptomatic OSA. IMT could be an adjuvant therapy for patients who are unwilling or unable to tolerate nightly CPAP.

\section{DATA AVAILABILITY STATEMENT}

The raw data supporting the conclusions of this article will be made available by the authors, without undue reservation.

\section{ETHICS STATEMENT}

The studies involving human participants were reviewed and approved by Saint-Etienne University Hospital ethics committee: CPP Sud Est I 1408189-2015-A00030-49. The patients/participants provided their written informed consent to participate in this study.

\section{AUTHOR CONTRIBUTIONS}

PL, MB, and DH: writing of original draft. All authors had a substantial contribution to the conception and design of the study. $\mathrm{PL}, \mathrm{MB}, \mathrm{AZ}, \mathrm{FR}$, and $\mathrm{DH}$ : responsible for data collection and formal analysis. $\mathrm{MB}, \mathrm{J}-\mathrm{CB}, \mathrm{FR}, \mathrm{DH}$, and AG: supervision. All authors contributed to the article and approved the submitted version.

\section{ACKNOWLEDGMENTS}

The authors thank the University Hospital of Saint Etienne which is the sponsor of this study. We would also like to thank all the patients for their kind participation in this study, the nurses of the service and the technician for their availability and their patience.

Anandam, A., Patil, M., Akinnusi, M., Jaoude, P., and El-Solh, A. A. (2013) Cardiovascular mortality in obstructive sleep apnoea treated with continuous positive airway pressure or oral appliance: an observational study. Respirology 18, 1184-1190. doi: 10.1111/resp.12140

Arzt, M., Young, T., Finn, L., Skatrud, J. B., Ryan, C. M., Newton, G. E., et al. (2006). Sleepiness and sleep in patients with both systolic heart failure and 
obstructive sleep apnea. Arch. Intern. Med. 166, 1716-1722. doi: 10.1001/ archinte.166.16.1716

Askland, K., Wright, L., Wozniak, D. R., Caston, T. E. J., and Smith, I. (2020). Educational, supportive and behavioural interventions to improve usage of continuous positive airway pressure machines in adults with obstructive sleep apnoea. Cochrane Database Syst. Rev. 2020:CD00773. doi: 10.1002/14651858.CD007736.PUB3

BenAhmed, H., Boussaid, H., Hamdi, I., and and. Boujnah, M.R., (2014). Prévalence et Facteurs Prédictifs Du Syndrome d'apnée Obstructive Du Sommeil Au Décours de l'infarctus Du Myocarde. Annales de Cardiologie et d'Angeiologie 63, 65-70. doi: 10.1016/j.ancard.2014.01.003

Berger, M., Barthélémy, J. C., Garet, M., Raffin, J., Labeix, P., Roche, F., et al. (2021). Longer-term effects of supervised physical activity on obstructive sleep apnea and subsequent health consequences. Scand. J. Med. Sci. Sports 31, 1534-1544. doi: 10.1111/SMS.13961

Berger, M., Barthélémy, J. C., Hupin, D., Raffin, J., Dupré, C., Labeix, P., et al. (2018). Benefits of supervised community physical activity in obstructive sleep apnoea. Eur. Respir. J. 52:1801592. doi: 10.1183/13993003.01592-2018

Berry, R. B., Budhiraja, R., Gottlieb, D. J., Gozal, D., Iber, C., Kapur, V. K., et al. (2012). Rules for scoring respiratory events in sleep: update of the 2007 AASM manual for the scoring of sleep and associated events. deliberations of the sleep apnea definitions task force of the American Academy of Sleep Medicine. J. Clin. Sleep Med. 8, 597-619. doi: 10.5664/JCSM.2172

Bradley, T. D., and Floras, J. S. (2009). Obstructive sleep apnoea and its cardiovascular consequences. 373, 82-93. Lancet. doi: 10.1016/S0140-6736(08)61622-0

Buysse, D. J., Reynolds, C. F., Monk, T. H., Berman, S. R., and Kupfer, D. J. (1989). The Pittsburgh sleep quality index: a new instrument for psychiatric practice and research. Psychiatry Res. 28, 193-213. doi: 10.1016/01651781(89)90047-4

Chouchou, F., Poupard, L., Philippe, C., Court-Fortune, I., Barthélémy, J. C., and Roche, F. (2013). Thoracic impedance, in association with oximetry, in a multi-modal ECG Holter system is useful for screening sleep disordered breathing. Int. J. Cardiol. 163, 100-102. doi: 10.1016/J.IJCARD. 2012.06.082

Coughlin, S. R., Mawdsley, L., Mugarza, J. A., Calverley, P. M. A., and Wilding, J. P. H. (2004). Obstructive sleep apnoea is independently associated with an increased prevalence of metabolic syndrome. Eur. Heart J. 25, 735-741. doi: 10.1016/j.ehj.2004.02.021

Desplan, M., Mercier, J., Sabaté, M., Ninot, G., Prefaut, C., and Dauvilliers, Y. (2014). A comprehensive rehabilitation program improves disease severity in patients with obstructive sleep apnea syndrome: a pilot randomized controlled study. Sleep Med. 15, 906-912. doi: 10.1016/J.SLEEP.2013.09.023

Dewan, N. A., Nieto, F., and J., and Somers, V.K., (2015). Intermittent hypoxemia and OSA: implications for comorbidities. Chest 147, 266-274. doi: 10.1378/ chest.14-0500

Fleury, B., Cohen-Levy, J., Lacassagne, L., Buchet, I., Geraads, A., Pegliasco, H., et al. (2010). Treatment of obstructive sleep apnea syndrome using a mandibular advancement device. Rev. Mal. Respir. 27, S146-S156. doi: 10.1016/ S0761-8425(10)70020-6

Fogel, R. B., Trinder, J., White, D. P., Malhotra, A., Raneri, J., Schory, K., et al. (2005). The effect of sleep onset on upper airway muscle activity in patients with sleep apnoea versus controls. J. Physiol. 564, 549-562. doi: 10.1113/JPHYSIOL.2005.083659

Garvey, J. F., Taylor, C. T., and McNicholas, W. T. (2009). Cardiovascular disease in obstructive sleep apnoea syndrome: the role of intermittent hypoxia and inflammation. Eur. Respir. J. 33, 1195-1205. doi: 10.1183/ 09031936.00111208

Giralt-Hernando, M., Valls-Ontañón, A., Guijarro-Martínez, R., Masià-Gridilla, J., and Hernández-Alfaro, F. (2019). Impact of surgical maxillomandibular advancement upon pharyngeal airway volume and the apnoea-hypopnoea index in the treatment of obstructive sleep apnoea: systematic review and meta-analysis. BMJ Open Respir. Res. 6:e00402. doi: 10.1136/bmjresp2019-000402

Guimarães, K. C., Drager, L. F., Genta, P. R., Marcondes, B. F., and Lorenzi-Filho, G. (2009). Effects of oropharyngeal exercises on patients with moderate obstructive sleep apnea syndrome. Am. J. Respir. Crit. Care Med. 179, 962-966. doi: 10.1164/rccm.200806-981OC

Heinzer, R., Vat, S., Marques-Vidal, P., Marti-Soler, H., Andries, D., Tobback, N., et al. (2015). Prevalence of sleep-disordered breathing in the general population: the HypnoLaus study. Lancet Respir. Med. 3, 310-318. doi: 10.1016/ S2213-2600(15)00043-0

How, S. C., McConnell, A. K., Taylor, B. J., and Romer, L. M. (2007). Acute and chronic responses of the upper airway to inspiratory loading in healthy awake humans: an MRI study. Respir. Physiol. Neurobiol. 157, 270-280. doi: 10.1016/J.RESP.2007.01.008

Hupin, D., Pichot, V., Berger, M., Sforza, E., Raffin, J., Lietar, C., et al. (2018). Obstructive sleep apnea in cardiac rehabilitation patients. J. Clin. Sleep Med. 14, 1119-1126. doi: 10.5664/JCSM.7206

Isono, S., Remmers, J. E., Tanaka, A., Sho, Y., Sato, J., and Nishino, T. (1997). Anatomy of pharynx in patients with obstructive sleep apnea and in normal subjects. J. Appl. Physiol. 82, 1319-1326. doi: 10.1152/JAPPL. 1997.82.4.1319

Javaheri, S., Barbe, F., Campos-Rodriguez, F., Dempsey, J. A., Khayat, R., Javaheri, S., et al. (2017). Sleep apnea: types, mechanisms, and clinical cardiovascular consequences. J. Am. Coll. Cardiol. 69, 841-858. doi: 10.1016/J.JACC.2016.11.069

Javaheri, S., Parker, T. J., Liming, J. D., Corbett, W. S., Nishiyama, H., Wexler, L., et al. (1998). Sleep apnea in 81 ambulatory male patients with stable heart failure: types and their prevalences, consequences, and presentations. Circulation 97, 2154-2159. doi: 10.1161/01.CIR.97.21.2154

Johns, M. W. (1991). A new method for measuring daytime sleepiness: the epworth sleepiness scale. Sleep 14, 540-545. doi: 10.1093/SLEEP/14.6.540

Kline, C. E., Crowley, E. P., Ewing, G. B., Burch, J. B., Blair, S. N., Durstine, J. L., et al. (2011). The effect of exercise training on obstructive sleep apnea and sleep quality: a randomized controlled trial. Sleep 34, 1631-1640. doi: 10.5665/ SLEEP.1422

Laveneziana, P., Albuquerque, A., Aliverti, A., Babb, T., Barreiro, E., Dres, M., et al. (2019). ERS statement on respiratory muscle testing at rest and during exercise. Eur. Respir. J. 53:1801214. doi: 10.1183/13993003.01214-2018

Libman, E., Bailes, S., Fichten, C. S., Rizzo, D., Creti, L., Baltzan, M., et al. (2017). CPAP treatment adherence in women with obstructive sleep apnea. Sleep Disord. 2017, 1-8. doi: 10.1155/2017/2760650

McEvoy, R. D., Antic, N. A., Heeley, E., Luo, Y., Ou, Q., Zhang, X., et al. (2016). CPAP for prevention of cardiovascular events in obstructive sleep apnea. N. Engl. J. Med. 375, 919-931. doi: 10.1056/NEJMOA1606599

Mooe, T., Franklin, K. A., Holmström, K., Rabben, T., and Wiklund, U. (2001). Sleep-disordered breathing and coronary artery disease: long-term prognosis. Am. J. Respir. Crit. Care Med. 164, 1910-1913. doi: 10.1164/ajrccm.164. 10.2101072

Oliven, R., Cohen, G., Somri, M., Schwartz, A. R., and Oliven, A. (2019). Peri-pharyngeal muscle response to inspiratory loading: comparison of patients with OSA and healthy subjects. J. Sleep Res. 28:e12756. doi: 10.1111/JSR.12756

Peker, Y., Hedner, J., Kraiczi, H., and Löth, S. (2000). Respiratory disturbance index: an independent predictor of mortality in coronary artery disease. Am. J. Respir. Crit. Care Med. 162, 81-86. doi: 10.1164/ajrccm.162.1. 9905035

Poupard, L., Mathieu, M., Sartène, R., and Goldman, M. (2008). Use of thoracic impedance sensors to screen for sleep-disordered breathing in patients with cardiovascular disease. Physiol. Meas. 29, 255-267. doi: 10.1088/0967$3334 / 29 / 2 / 008$

Puhan, M. A., Suarez, A., Lo Cascio, C., Zahn, A., Heitz, M., and Braendli, O. (2006). Didgeridoo playing as alternative treatment for obstructive sleep apnoea syndrome: randomised controlled trial. BMJ 332, 266-270. doi: 10.1136/bmj.38705.470590.55

Ramos-Barrera, G. E., DeLucia, C. M., and Bailey, E. F. (2020). Inspiratory muscle strength training lowers blood pressure and sympathetic activity in older adults with OSA: a randomized controlled pilot trial. J. Appl. Physiol. 129, 449-458. doi: 10.1152/japplphysiol.00024.2020

Roche, F., Duverney, D., Court-Fortune, I., Pichot, V., Costes, F., Lacour, J. R. et al. (2002). Cardiac interbeat interval increment for the identification of obstructive sleep apnea. Pacing Clin. Electrophysiol. 25, 1192-1199. doi: 10.1046/J.1460-9592.2002.01192.X

Roche, F., Gaspoz, J. M., Court-Fortune, I., Minini, P., Pichot, V., Duverney, D., et al. (1999). Screening of obstructive sleep apnea syndrome by heart rate variability analysis. Circulation 100, 1411-1415. doi: 10.1161/01.CIR.100. 13.1411

Rotenberg, B. W., Murariu, D., and Pang, K. P. (2016). Trends in CPAP adherence over twenty years of data collection: a flattened curve. J. Otolaryngol. Head Neck Surg 45:43. doi: 10.1186/S40463-016-0156-0 
Sengul, Y. S., Ozalevli, S., Oztura, I., Itil, O., and Baklan, B. (2009). The effect of exercise on obstructive sleep apnea: a randomized and controlled trial. Sleep Breath. 15, 49-56. doi: 10.1007/S11325-009-0311-1

Sforza, E., Pichot, V., Cervena, K., Barthélémy, J. C., and Roche, F. (2007). Cardiac variability and heart-rate increment as a marker of sleep fragmentation in patients with a sleep disorder: a preliminary study. Sleep 30, 43-51. doi: 10.1093/SLEEP/30.1.43

Sin, D. D., Mayers, I., Man, G. C. W., and Pawluk, L. (2002). Long-term compliance rates to continuous positive airway pressure in obstructive sleep apnea a population-based study. Chest 121, 430-435. doi: 10.1378/ chest.121.2.430

Souza, A. K. F., Dornelas de Andrade, A., Carlos de Medeiros, A. I., Remígio de Aguia, M. I. R., Dias de Souza Rocha, T., Pinto Pedrosa, R., et al. (2018). Effectiveness of inspiratory muscle training on sleep and functional capacity to exercise in obstructive sleep apnea: a randomized controlled trial. Sleep Breathing 22, 631-639. doi: 10.1007/s11325-017-1591-5

Tietjens, J. R., Claman, D., Kezirian, E. J., de Marco, T., Mirzayan, A., Sadroonri, B., et al. (2019). Obstructive sleep apnea in cardiovascular disease: a review of the literature and proposed multidisciplinary clinical management strategy. J. Am. Heart Assoc. 8:e010440. doi: 10.1161/JAHA.118.010440

Vranish, J. R., and Bailey, E. F. (2016). Inspiratory muscle training improves sleep and mitigates cardiovascular dysfunction in obstructive sleep apnea. Sleep 39, 1179-1185. doi: 10.5665/sleep.5826
Ward, C. P., York, K. M., and McCoy, J. G. (2012). Risk of obstructive sleep apnea lower in double reed wind musicians. J. Clin. Sleep Med. 8, 251-255. doi: $10.5664 /$ jcsm.1906

Ware, J. Jr., Kosinski, M., and Keller, S. D. (1996). A 12-item short-form health survey: construction of scales and preliminary tests of reliability and validity. Med. Care 34, 220-233.

Conflict of Interest: The authors declare that the research was conducted in the absence of any commercial or financial relationships that could be construed as a potential conflict of interest.

Publisher's Note: All claims expressed in this article are solely those of the authors and do not necessarily represent those of their affiliated organizations, or those of the publisher, the editors and the reviewers. Any product that may be evaluated in this article, or claim that may be made by its manufacturer, is not guaranteed or endorsed by the publisher.

Copyright (c) 2022 Labeix, Berger, Zellag, Garcin, Barthelemy, Roche and Hupin. This is an open-access article distributed under the terms of the Creative Commons Attribution License (CC BY). The use, distribution or reproduction in other forums is permitted, provided the original author(s) and the copyright owner(s) are credited and that the original publication in this journal is cited, in accordance with accepted academic practice. No use, distribution or reproduction is permitted which does not comply with these terms. 